\title{
Four-Array Printed Monopole Yagi-Uda Antenna Mounted on a Small Missile Warhead
}

\author{
Dong-Su Choi ${ }^{1} \cdot$ Yoon-Seon Choi ${ }^{1} \cdot$ Jae-Yeop Jeong $^{2} \cdot$ Tae-Hwan Jung $^{3} \cdot$ Jong-Myung Woo ${ }^{1,}$
}

\begin{abstract}
In this study, the structure of a circular four-array antenna was designed for a monopulse radar attached to a conical small missile warhead with a diameter of $29 \mathrm{~mm}$ and a lateral length of $63 \mathrm{~mm}$. A printed monopole Yagi-Uda antenna was adopted as the basic model for the antenna to decrease production cost and reduce weight. The director structure of the printed monopole Yagi-Uda antenna that we proposed was modified to $\lambda / 2$ to improve the beam direction. Unlike the existing structure, the proposed director was made to be separated from the ground, so that it could act as a director. The antenna was expanded to a four-array structure for the detection of vertical and horizontal planes. As a result of the design, the $S_{11}$ had excellent matching characteristics at the center frequency of $9.375 \mathrm{GHz}$, and the beam pattern also had directivity in the same direction as the missile travel direction. In the case of gain, it showed more than $6 \mathrm{dBi}$ performance. Finally, the proposed four-array structure antenna was fabricated to verify that the $S_{11}$ and radiation patterns were maintained.
\end{abstract}

Key Words: Missile Antenna, Printed Monopole Yagi-Uda Antenna, Sum and Difference Pattern, Tracking Antenna.

\section{INTRODUCTION}

Missile accuracy is directly affected by the performance of the radar mounted on the missile. On a large missile, an array of slot antennas or a patch antenna structure is typically used for the missile's radar [1-3]. Antennas with this type of structure are generally mounted with a phase shifter on the back end of the antenna, which tracks and intercepts an object by modifying the beam directing angle. Since such systems are large and relatively expensive, they are not suitable for mounting on a small missile for tracking a small object. Instead, a semi-active-type radar, which only has a receiver module, is employed on small missiles [4].
Among such semi-active-type radar systems, one of the representative antenna designs applied to the surfaces of small missiles is the sub-wavelength-aperture monopulse conformal antenna patented by Lockheed Martin [5]. This antenna is produced by modifying a bull's eye antenna, and to control the missile's flight direction, the beam angle is steered using a dielectric. Detection is performed by the monopulse method utilizing four antenna arrays on the warhead surface. However, when the beam direction setup is modified in the basic bull's eye antenna, the side lobe level is increased, resulting in a complicated structure and high manufacturing cost [6]. In [7], patch antenna used for the transmission and reception module can also be mounted on the sharp and the structure is simple, the missile

Manuscript received September 5, 2020 ; Revised December 14, 2020 ; Accepted January 28, 2021. (ID No. 20200905-134J)

${ }^{1}$ Department of Radio and Information Communication Engineering, Chungnam National University, Daejeon, Korea.

${ }^{2}$ The Attached Institute of Electronics and Telecommunications Research Institute (ETRI), Daejeon, Korea.

${ }^{3}$ Land Radar Team, Hanwha Systems, Yongin, Korea.

"Corresponding Author: Jong-Myung Woo (e-mail: jmwoo@cnu.ac.kr)

This is an Open-Access article distributed under the terms of the Creative Commons Attribution Non-Commercial License (http://creativecommons.org/licenses/by-nc/4.0) which permits unrestricted non-commercial use, distribution, and reproduction in any medium, provided the original work is properly cited.

(c) Copyright The Korean Institute of Electromagnetic Engineering and Science. All Rights Reserved. 
surface. Although the beam is sharp and the structure is simple, the antenna beam direction does not match the missile's travel direction. Therefore, this is inadequate for use as an antenna for a monopulse radar.

In this study, a position tracking antenna is proposed for use in such radar systems, by using a printed monopole Yagi-Uda antenna that can be mounted on the warhead of a small missile. The antenna can be manufactured by a simple method, and the cost of manufacturing is low. In addition, the beam pattern can be easily modified, and the gain can be easily improved by using a reflector and a director. Moreover, since its shape is easily changed, a printed monopole Yagi-Uda antenna can be easily mounted on the surface of a missile warhead. The typical printed Yagi-Uda antenna uses $\lambda / 2$ dipole as driven elements $[8,9]$. Such a structure requires a balun or an additional ground on the dipole, resulting in a complex or large structure. To solve this problem, we studied a new structure in which the feeding element is a monopole [10-18], which has the symmetry pattern in the broadside direction. However, while this had a simpler structure than the existing Yagi-Uda antenna, it is not suitable for use as a monopulse because the beam does not point in the endfire direction due to the ground effect. To overcome these shortcomings, we proposed a printed Yagi-Uda antenna that can be used as a monopulse radar antenna by applying a $\lambda / 2$ director to a missile warhead.

\section{ANTENNA DESIGN}

Fig. 1 shows the design structure of the antenna proposed in

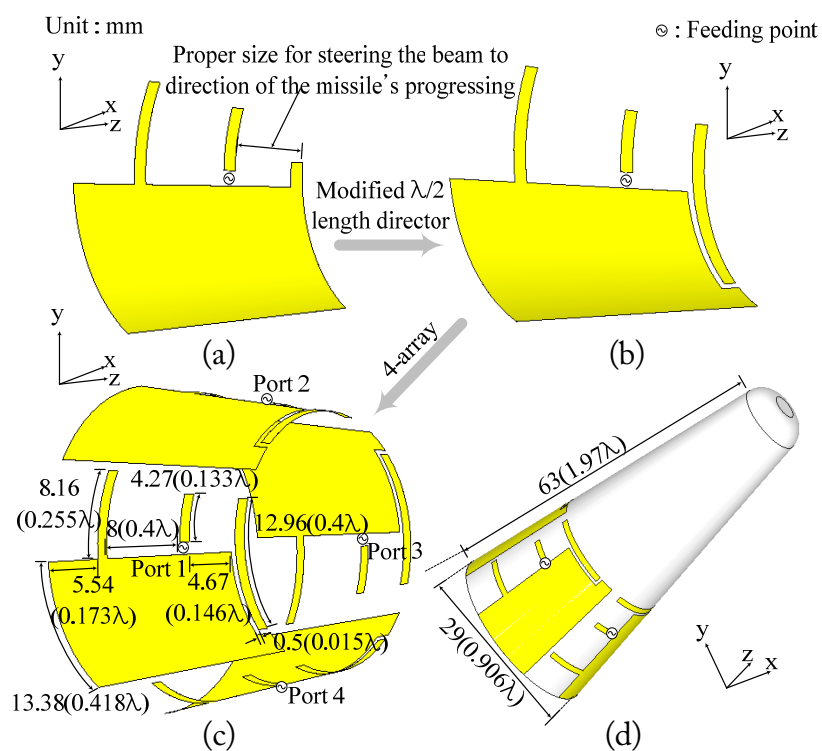

Fig. 1. Structure of the proposed antenna: (a) $\lambda / 4$ director monopole Yagi-Uda antenna, (b) transferred $\lambda / 2$ director monopole Yagi-Uda antenna, (c) four-array transferred $\lambda / 2$ director monopole Yagi-Uda antenna, and (d) missile warhead mounted shape. this study. Fig. 1(a) shows the structure with the front part removed in the antenna proposed in [10]. This is to align the beam direction with the missile's travel direction. The antenna director shown in Fig. 1(a) did not perform properly. To solve this problem, a $\lambda / 2$ director is proposed, as shown in Fig. 1(b). The director attached to the ground was manufactured with a $0.5 \mathrm{~mm}$ gap from the ground. The structure shown in Fig. 1(c) is the four-array version of the structure shown in Fig. 1(b).

Fig. 1(d) shows the three-dimensional shape of the structure mounted on a warhead. The diameter of the bottom surface of the conical warhead was determined to be $29 \mathrm{~mm}$. The antenna was attached to the back end in order to keep the beam direction of the antenna aligned with the missile direction.

Fig. 2 shows the change in gain at $0^{\circ}$ when the length of the director of the Fig. 1(c) antenna is swept. Below $0.4 \lambda$, it can be seen that the gain increases as the length of the director increases. Above $0.4 \lambda$, it can be seen that the gain decreases as the length increases. This is because when the element length becomes larger than a certain length, it operates as a reflector rather than a director. Therefore, in this study, a director of $0.4 \lambda$ length was designed with the maximum gain. Moreover, the gain change was simulated by changing the distance from the driven element from 0.5 to $2.5 \mathrm{~mm}$ in $0.5 \mathrm{~mm}$ increments. As a result, the difference between the maximum and minimum values was $0.33 \mathrm{~dB}$. Accordingly, it was confirmed that the distance between the ground and the director does not have a significant effect on gain.

Fig. 3 shows the structure of the manufactured antenna. Coated paper was attached to both sides of the antenna to realize curvature. Two of the antennas are used to detect the vertical plane, while the other two are used to detect the horizontal plane.

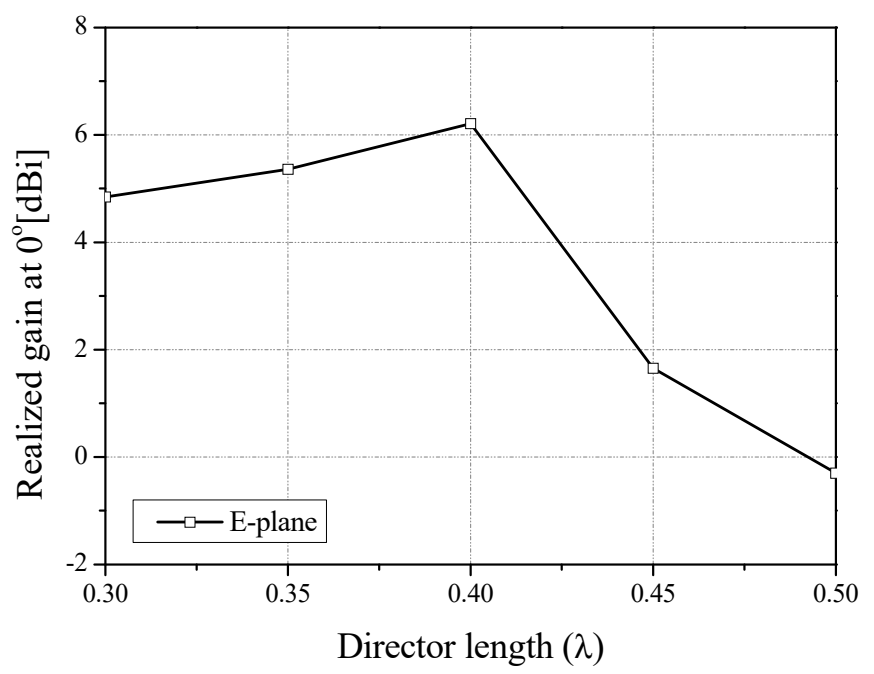

Fig. 2. Realized gain at $0^{\circ}$ according to director length. 


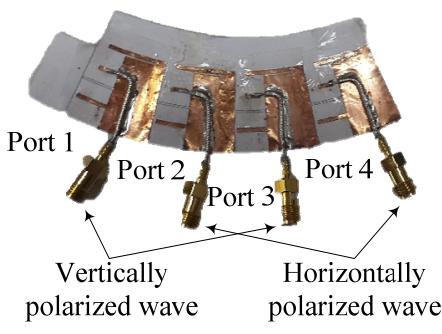

(a)

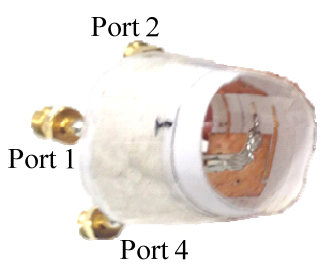

(b)
Fig. 3. Manufactured antenna: (a) unfolded form and (b) folded form.

\section{SIMULATED AND MEASURED RESULTS}

Fig. 4 shows the simulated (CST Studio Suite, https://www. cst.com) current distribution of the antennas shown in Fig. 1(a) and (b). Fig. 4(a) shows that the current of the director does not flow independently and flows along the ground and does not act as a director. In contrast, the current flow shown in Fig. 4(b) reveals that the current of the director flows in the direction opposite to the feed and operates normally as a director.

Fig. 5 shows the comparison between the $S_{11}$ simulation value and the $S_{11}$ graph of the four ports of the manufactured antenna. Both simulation and measurement values had excellent matching characteristics of $-20 \mathrm{~dB}$ or more at $9.375 \mathrm{GHz}$. The measured bandwidth was slightly narrower than the simulated bandwidth of $1,332 \mathrm{MHz}$, because the ground height of the

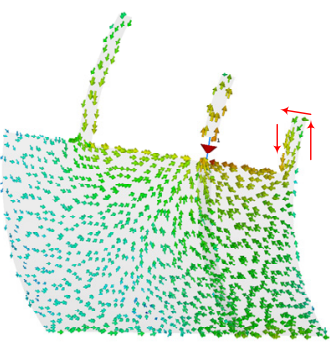

(a)

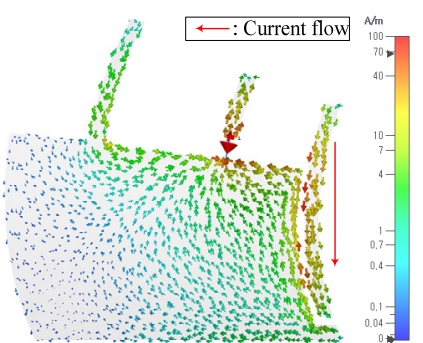

(b)
Fig. 4. Current flow: (a) Fig. 1(a) antenna and (b) Fig. 2(b) antenna.

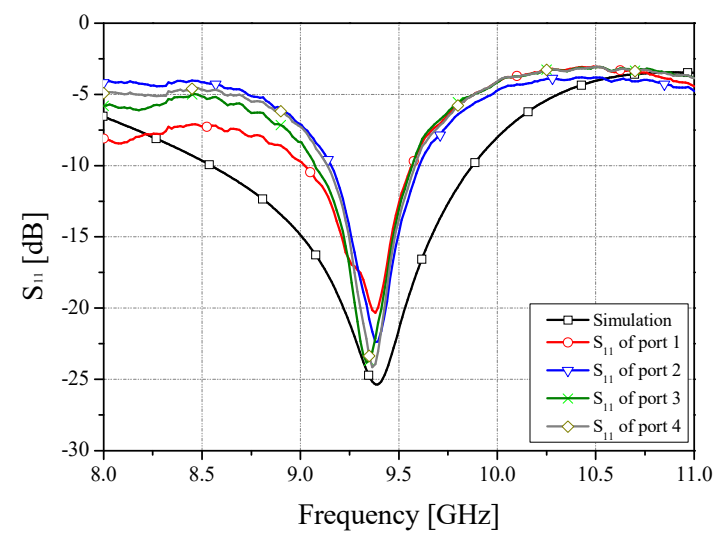

Fig. 5. $S_{11}$ of Fig. 1(c) antenna. manufactured antenna was larger than that in the simulation. As the area of the ground plane increases, this effect decreases relatively and thus the tendency of bandwidth increase decreases significantly as the ground plane effect is enhanced. In Fig. 6(a) and (b), the radiation patterns of the Fig. 1(a)-(c) antennas are compared and shown. When changing from the director structure in Fig. 1(a) to the director structure in Fig. 2(b), the $0^{\circ}$ gain increased by $1.58 \mathrm{dBi}$ from $4.36 \mathrm{dBi}$ to $5.94 \mathrm{dBi}$. The four-array structure shown in Fig. 1(c) showed an even better gain of 6.24 dBi. Fig. 6(c) and (d) show the comparison between the simulation and the measured values. Result showed that the front beam pattern and gain were similar. Other directions had different beam patterns, which are considered to be different in the feeding method of simulation and measurement. Table 1 shows the comparison of maximum gain between the simulation and measurement. It can be seen that all four ports have gains similar to the simulation.

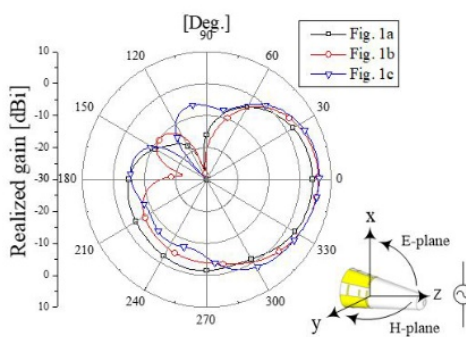

(a)

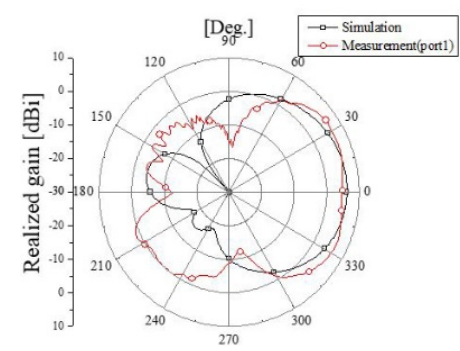

(c)

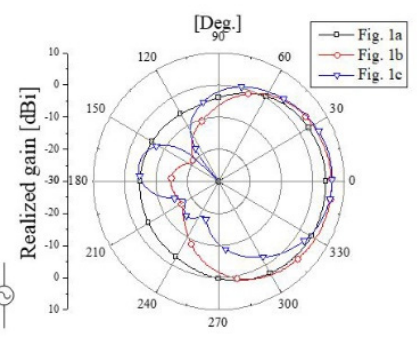

(b)

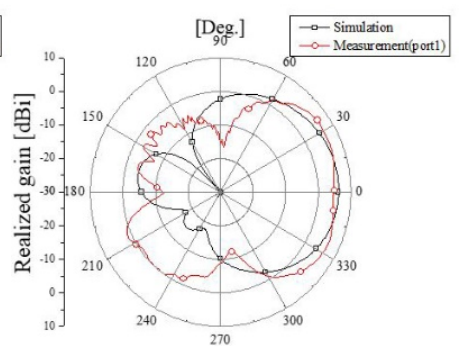

(d)

Fig. 6. Comparison of radiation patterns: (a) simulation E-plane comparison of Fig. 1(a)-(c) antennas, (b) simulation Hplane comparison of Fig. 1(a)-(c) antennas, (c) E-plane comparison of Fig. 1(c) antenna simulation and measurement, and (d) H-plane comparison of Fig. 1(c) antenna simulation and measurement.

Table 1. Total efficiency levels and peak gains of the designed antenna

\begin{tabular}{lccccc}
\hline & \multicolumn{5}{c}{ Maximum gain (dBi) } \\
\cline { 2 - 6 } & Simulation & \multicolumn{4}{c}{ Measurement } \\
\cline { 3 - 6 } & & Port 1 & Port 2 & Port 3 & Port 4 \\
\hline E-plane & 6.24 & 6.41 & 6.19 & 6.18 & 6.35 \\
H-plane & 6.24 & 6.63 & 6.42 & 6.13 & 5.98 \\
\hline
\end{tabular}




\section{CONCLUSION}

In the present study, a four-array antenna was proposed for a small missile radar that can be mounted on a conical warhead. The antenna adopts the printed Yagi-Uda antenna as the basic structure to solve the complex structure, which is the disadvantage of the general Yagi-Uda antenna. In addition, a $\lambda / 2$ director was applied to improve the beam direction, which is a disadvantage of the printed monopole Yagi-Uda antenna. Unlike the existing structure, the director is positioned in front of the ground so that current flows independently and can function as a director. As a result of the design, $S_{11}$ has excellent matching characteristics of $-20 \mathrm{~dB}$ or more at the center frequency of $9.375 \mathrm{GHz}$ in the simulation and manufacture. In addition, in the case of the radiation pattern, it has a characteristic that is directed in the same direction as the missile travel direction, and in the case of gain, both simulation and production values have excellent performance of $6 \mathrm{dBi}$ or more. As a result of the design, the simulation has a maximum gain of $6.24 \mathrm{dBi}$, and the manufactured antenna has a similar gain of $6 \mathrm{dBi}$ or more. For this reason, the antenna proposed in this study can be mounted on a missile warhead and used as an antenna for radar.

\section{REFERENCES}

[1] H. S. Lee and J. M. Woo, "A study on the aerial vehicle mounted antenna," in Proceedings of KIEES Microwave and Electromagnetic Wave Communication Conference, 1999, pp. 141-144.

[2] H. J. Visser, Array and Phased Array Antenna Basics. New York, NY: John Wiley \& Sons Inc., 2005.

[3] K. B. Kim, B. C. Jung, and J. M. Woo, "A compact dualpolarized (CP, LP) with dual-feed microstrip patch array for target detection," IEEE Antennas and Wireless Propagation Letters, vol. 19, no. 4, pp. 517-521, 2020.

[4] D. Ciampa and D. Bucco, "The performance of semi-active radar guided missiles against sea skimming target," Defence Science and Technology Organization, Canberra, Australia, 1995.

[5] B. A. Williams, "Subwavelength aperture monopulse conformal antenna," US Patent 8,354,953, Jan 15, 2013.

[6] C. J. Vourch and T. D. Drysdale, "V-band "Bull's eye" antenna for cubesat application," IEEE Antenna and Wireless Propagation Letters, vol. 13, pp. 1092-1095, 2014.

[7] V. Jaeck, L. Bernard, K. Mahdjoubi, R. Sauleau, S. Collardey, P. Pouliguen, and P. Potier, "A conical patch antenna array for agile point-to-point communications in the 5.2$\mathrm{GHz}$ band," IEEE Antenna and Wireless Propagation Letters, vol. 15, pp. 1230-1233, 2016.

[8] M. Nasir, Y.Xia, M. Jiang, and Q.Zhu, "A novel integrated Yagi-Uda and dielectric rod antenna with low sidelobe level," IEEE Transactions on Antennas and Propagation, vol. 67, no. 4, pp. 2751-2756, 2019.

[9] B. K. Tehrani, B. S. Cook, and M. M. Tentzeris, "Inkjet printing of multilayer millimeter-wave Yagi-Uda antennas on flexible substrates," IEEE Antennas and Wireless Propagation Letters, vol. 15, pp. 143-146, 2015.

[10] H. S. Ham, Y. R. Kim, and J. M. Woo, "Active printed inverted F antenna for beam steering," in Proceedings of 2007 IEEE Antennas and Propagation Society International Symposium, Honolulu, HI, 2007, pp. 3348-3351.

[11] S. M. Moon, J. M. Woo, and H. C. Shin, "Printed monopole Yagi-Uda antenna," in Proceedings of KIEES Fall Microwave and Propagation Conference, 2001.

[12] S. M. Lee, N. E. Sung, and J. M. Woo, "Printed active Yagi-Uda antenna," in Proceedings of KIEES Spring Microwave and Propagation Conference, 2002, pp. 169-172.

[13] H. S. Ham, S. M. Moon, and J. M. Woo, "Printed beam steering active antenna mounted on a vehicle," in Proceedings of the Korea Institute of Military Science and Technology Conference, 2005, pp. 165-168.

[14] H. S. Ham, S. M. Moon, J. C. Kim, and J. M. Woo, "Characteristics of a printed beam steering active YagiUda antenna mounted on an aircraft model," in Proceedings of Summer Microwave and Propagation Conference, 2006, pp. 252-252.

[15] J. M. Lee and J. M. Woo, "Design of GPS receiving antenna installed in a missile's warhead," Journal of Korean Institute of Electromagnetic Engineering and Science, vol.17, no. 9, pp. 900-912, 2006.

[16] S. K. Han, J. Y. Park, and J. M. Woo, "Printed folded monopole Yagi-Uda antenna," in Proceedings of KIEES Microwave and Lightwave Technology Conference, 2007,pp. 41-44.

[17] D. H. Shin, Y. S. Choi, and J. M. Woo, "Missile mounted beam steering print type inverted $\mathrm{F}$ antenna design," in Proceedings of KIEES Microwave and Lightwave Technology Conference, 2014, pp. 27-28.

[18] J. M. Woo, "Aerial vehicle mounted antenna," in Proceedings of KIEES Microwave and Electromagnetic Wave Communication Conference, 2020, pp. 26-26. 


\section{Dong-Su Choi}

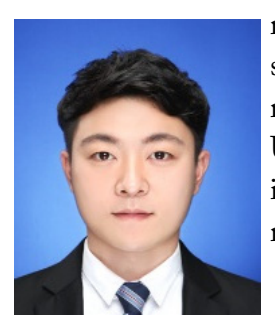

received his B.S. degrees in physics from Gyeongsang National University in 2013 and M.S. degrees in radiowave engineering from Chungnam National University in 2019, respectively. He is currently working toward his $\mathrm{Ph} . \mathrm{D}$. degree at the antenna laboratory. His main research interest is antennas.

\section{Yoon-Seon Choi}

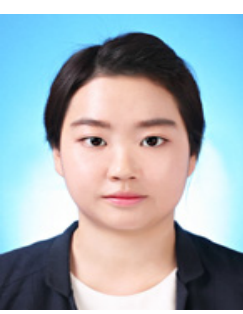

received her B.S. and M.S. degrees in radiowave engineering from Chungnam National University in 2014 and 2016, respectively. She is currently working toward her Ph.D. degree at the antenna laboratory. Her main research interest is antennas.

\section{Jae-Yeop Jeong}

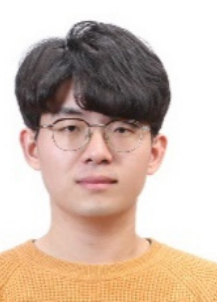

received his B.S. and M.S. degrees in radiowave engineering from Chungnam National University in 2015 and 2017, respectively. He is currently working as a researcher in the attached institute of ETRI. His main research interest is antennas.

\section{Tae-Hwan Jung}

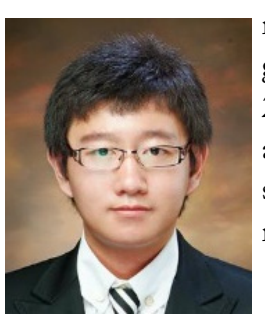

received his B.S. and M.S. degrees in radiowave engineering from Chungnam National University in 2012 and 2014, respectively. He is currently working about land radar as a senior engineer in Hanwha systems. His main research interest are antennas and radar.

\section{Jong-Myung Woo}

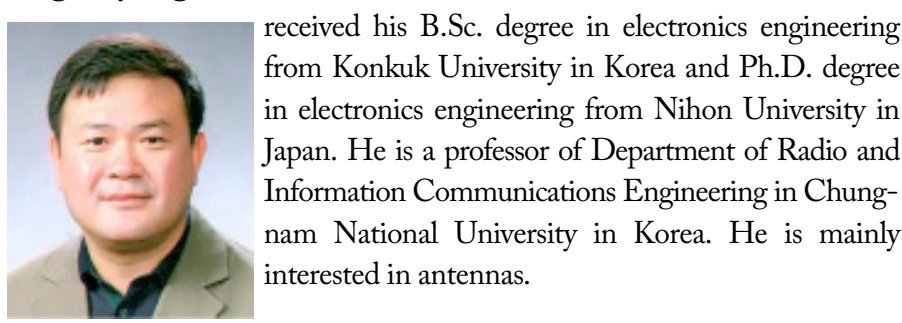

